\title{
Erratum to: Morphological and molecular differentiation of two new species of Pseudoacanthocephalus Petrochenko, 1958 (Acanthocephala: Echinorhynchidae) from amphibians and reptiles in the Philippines, with identification key for the genus
}

\author{
Vasyl V. Tkach • Olga I. Lisitsyna • \\ Janna L. Crossley • Tran Thi Binh • \\ Sarah E. Bush
}

(C) Springer Science+Business Media Dordrecht 2013

Erratum to: Syst Parasitol (2013) 85:11-26

DOI 10.1007/s11230-013-9409-8

In the original publication of the article, the specific name of a new taxon, Pseudoacanthocephalus smalesi,

The online version of the original article can be found under doi:10.1007/s11230-013-9409-8.

\section{V. Tkach ( $\square)$}

Department of Biology, University of North Dakota, 10 Cornell Street, Grand Forks, ND 58202, USA

e-mail: vasyl.tkach@email.und.edu

\section{O. I. Lisitsyna}

Schmalhausen Institute of Zoology, Ukrainian National Academy of Sciences, 15 Bohdan Khmelnitsky Street, 01601 Kiev, Ukraine

J. L. Crossley

Department of Biological Sciences, University of North Texas, 1511 West Sycamore St., Denton, TX 76203, USA was mis-spelled. The correct spelling of this species is Pseudoacanthocephalus smalesae. The authors and the editor apologise for this lapsus calami. 